ORIGINAL ARTICLE

\title{
Reverse cascade screening of newborns for hereditary haemochromatosis: a model for other late onset diseases?
}

\author{
E Cadet, D Capron, M Gallet, M-L Omanga-Léké, H Boutignon, C Julier, K J H Robson, J Rochefte
}

J Med Genet 2005;42:390-395. doi: 10.1136/jmg.2004.027284

See end of article for authors' affiliations

.....................

Correspondence to: Professor J Rochette, Department of Medical Genetics and UMR-INERIS, Centre HospitaloUniversitaire et Faculté de Médecine, 3 rue des Louvels, 80036, Amiens, France; jacques.rochette@ u-picardie.fr

Received

17 September 2004

Revised 8 December 2004

Accepted

13 December 2004

\begin{abstract}
Background: Genetic testing can determine those at risk for hereditary haemochromatosis $(\mathrm{HH})$ caused by HFE mutations before the onset of symptoms. However, there is no optimum screening strategy, mainly owing to the variable penetrance in those who are homozygous for the HFE Cys282Tyr (C282Y) mutation. The objective of this study was to identify the majority of individuals at serious risk of developing HFE haemochromatosis before they developed life threatening complications.

Methods: We first estimated the therapeutic penetrance of the C282Y mutation in people living in la Somme, France, using genetic, demographic, biochemical, and follow up data. We examined the benefits of neonatal screening on the basis of increased risk to relatives of newborns carrying one or two copies of the C282Y mutation. Between 1999 and 2002, we screened 7038 newborns from two maternity hospitals in the north of France for the C282Y and His63Asp (H63D) mutations in the HFE gene, using bloodspots collected on Guthrie cards. Family studies and genetic counselling were undertaken, based on the results of the baby's genotype.

Findings: In la Somme, we found that $24 \%$ of the adults homozygous for the C282Y mutation required at least $5 \mathrm{~g}$ iron to be removed to restore normal iron parameters (that is, the therapeutic penetrance). In the reverse cascade screening study, we identified 19 C282Y homozygotes (1/370), 491 heterozygotes $(1 / 14)$ and 166 compound heterozygotes (1/42) in 7038 newborns tested. The reverse cascade screening strategy resulted in 80 adults being screened for both mutations. We identified 10 previously unknown $\mathrm{C} 282 \mathrm{Y}$ homozygotes of whom six (four men and two women) required venesection. Acceptance of neonatal screening was high; parents understood the risks of having $\mathrm{HH}$ and the benefits of early detection, but a number of parents were reluctant to take the test themselves. Neonatal screening for $\mathrm{HH}$ is straightforward. Reverse cascade screening increased the efficiency of detecting affected adults with undiagnosed haemochromatosis. This strategy allows almost complete coverage for $\mathrm{HH}$ and could be a model for efficient screening for other late onset genetic diseases.
\end{abstract}

$\mathrm{H}$ ereditary haemochromatosis $(\mathrm{HH})$ caused by mutations in HFE is a common autosomal recessive disorder of iron metabolism in people of northern European extraction. Often, middle aged patients present with early clinical symptoms of general fatigue, arthralgia, and arthritis, which are not specific to HH. Liver disease, diabetes, and impotence are complications that arise later. ${ }^{1}$ In northern France, about $85 \%$ of patients with $\mathrm{HH}$ are homozygous for the Cys282Tyr (C282Y) mutation in HFE. ${ }^{2}$ The role of a second mutation, the substitution of histidine by aspartic acid at position 63 (H63D) is unclear. ${ }^{3}$ There are a number of arguments favouring preventative screening for haemochromatosis in northern European populations: (a) 2-5 of every 1000 individuals in the North of Europe are homozygotes for the C282Y mutation (genotype HH/YY), (b) normal life expectancy can be restored if iron is removed by venesection in the pre-cirrhotic stage; and (c) premature death results if $\mathrm{HH}$ remains undetected for too long. ${ }^{4}$ Despite the fact that $\mathrm{HH}$ can be considered as a model genetic disorder for screening and disease prevention, there is no consensus regarding the optimal screening strategy. ${ }^{5-7}$ The challenge is how to identify the majority of individuals at serious risk of developing iron overload before they develop life threatening complications.

The diagnostic utility of a single measurement of iron status, (such as percentage transferrin saturation $\left(\% \mathrm{~T}_{\text {sat }}\right)$ or unbound iron binding capacity test) varies with the age of testing. ${ }^{8}$ Disease is accompanied by increased serum ferritin levels, which unfortunately are also associated with a number of other conditions. Repeated biochemical testing is recommended, but this is costly. ${ }^{70}$ Although men show signs of the disease earlier than women, there is a wide age range associated with the onset of symptoms in both sexes. ${ }^{11}$ For these reasons, the optimum age for screening adults using serum iron parameters has yet to be established.

Genetic screening is an alternative but it raises ethical, political, and economic issues. In particular, the incomplete penetrance of the $\mathrm{C} 282 \mathrm{Y}$ mutation in homozygotes raises problems as to the definition of the disease and when to treat. ${ }^{12-17}$ Other genotypes are occasionally associated with the disease. ${ }^{18}$ There are a number of reports describing low levels of clinical penetrance in C282Y homozygotes. ${ }^{15}{ }^{17}$ These findings in particular have suggested that it is not cost effective to undertake population screening for haemochromatosis. On the other hand, there are other reports suggesting that there are much higher levels of mutation penetrance elsewhere. ${ }^{19}$ Should the definition of penetrance depend upon abnormal biochemical parameters or should it also include clinical disease? One of the main reasons for instigating a screening programme for haemochromatosis is that disease prevention and hence, any screening strategy, needs to identify patients in the early pre-clinical phase before irreversible end organ damage has occurred. If widespread population screening is to be cost effective for

Abbreviations: $\mathrm{CF}$, cystic fibrosis; $\mathrm{HH}$, hereditary haemochromatosis; $\mathrm{PKU}$, phenylketonuria 
haemochromatosis, it is important to understand the nature of disease penetrance in that particular population.

If the degree of penetrance is high, then this provides a justification for some form of population screening. Genetic screening is not age dependent and could be particularly cost effective if it could be incorporated with DNA screening for other diseases such as cystic fibrosis (CF). The ability to follow a cohort over time and see if and when the members develop clinical disease will also help in understanding penetrance in haemochromatosis when presentation is so variable. Another advantage of a neonatal screening programme for haemochromatosis is that it also permits the application of reverse cascade screening.

Cascade screening is used to identify asymptomatic individuals who are at risk of developing a disease because they have an affected relative. Reverse cascade screening identifies the asymptomatic individual first and uses this information to identify undiagnosed affected relatives.

We analysed the number of C282Y homozygotes identified in the Somme département of France over a 4 year period, and identified those who required the removal of more than $5 \mathrm{~g}$ of iron by quantitative phlebotomy, using the iron burden to define therapeutic penetrance. In a population in which $50 \%$ of C282Y homozygotes express disease, then $40 \%$ of homozygotes should be detected by screening first to third degree relatives of $\mathrm{C} 282 \mathrm{Y}$ homozygotes. ${ }^{20}$ On the other hand, if penetrance is lower, with $25 \%$ of the C282Y homozygotes showing signs of iron burden, the number of at risk individuals detected by reverse cascade screening falls to $24 \% .{ }^{20}$ This then reduces the number of people to be tested to identify a single at risk individual.

Therefore, as an alternative to phenotypic screening, we investigated the advantages of neonatal screening for $\mathrm{HH}$ followed by screening for the variants in parents and other relatives when the neonate was identified as heterozygous or homozygous for the at risk genotype (that is, "reverse" cascade screening). The advantage of this strategy is that it identifies a target population of relatives who have an increased risk of $\mathrm{HH}$.

\section{MATERIALS AND METHODS Penetrance of the C282Y homozygous genotype in the adult population}

Available data regarding the Somme district were extracted from the Institut National des Statistiques et des Études Économiques and from the Institut National des Études Démographiques, Paris, France. We estimated the penetrance of the C282Y mutation during the period 1996-2000 using demographic, biochemical, genetic, and phlebotomy records in patients having the HH/YY genotype in our département. We defined a fully penetrant genotype as one requiring the removal of a minimum of $5 \mathrm{~g}$ of iron to return serum iron parameters to normal. Using this information, we instigated a neonatal screening study for $\mathrm{HH}$.

\section{Neonatal study design}

Both local and national ethics permission were obtained, with the following qualifications: the national ethics committee asked that all parents should have access to their child's results, and the local research ethics committee restricted the length of the study to 3 years. The work was approved by the Ministry of Health (registered no. DGS 2002/ 0366) and insured as required for research programmes involving genetic testing of no immediate benefit (Biomedicinsure no. 200300035; Gerling Co., France). This insurance policy protects the hospital against claims of negligence that might be filed at a later date by the parents.

Neonatal screening was conducted at two maternity hospitals in Picardie (northern France, including the
Somme département) between 1999 and 2002. Medical staff (paediatricians and nurses) attended a series of seminars on neonatal screening and $\mathrm{HH}$ with 6 monthly updates.

When each baby was 1 day old, parents were given a four page leaflet describing the genetics of $\mathrm{HH}$ and its complications, supplemented on the second day by verbal information including a question and answer session. The time taken (5-30 minutes) depended on the parents' understanding of genetics. Participation in the programme was entirely voluntary, with a clear explanation that the results of the screen would initially benefit parents and relatives. Implications of the at risk genotype (HH/YY) and its ramifications for their baby were explained to parents.

Consent was modified as new genes involved in haemochromatosis were described. Initially, however, it was made clear to parents that screening was restricted to the $\mathrm{C} 282 \mathrm{Y}$ and H63D mutations in the HFE gene and that the study did not include a test for neonatal haemochromatosis. Parents were given 2 days to accept or refuse the genetic test for their baby. When informed consent from both parents was obtained, on the third day after birth blood was spotted onto a Guthrie card that forms part of the routine screening for phenylketonuria (PKU), hypothyroidism, and CF. Local general practitioners and paediatricians practising in the private sector also received written information from the local social security system concerning this 3 year research programme for $\mathrm{HH}$ neonatal screening. Three annual continuing medical education conferences on haemochromatosis, its management, and reverse cascade screening were organised in the medical school for all local clinicians.

\section{Genetic studies}

DNA was extracted from a Guthrie card spot with the QIAamp Blood kit (Qiagen SA, Courtaboeuf, France) using the specified protocol for dried blood. As previously described, ${ }^{21}{ }^{22} 10 \mu \mathrm{l}$ of the eluted DNA (75-100 ng) were used for genotyping the $\mathrm{C} 282 \mathrm{Y}$ and H63D mutations with appropriate controls.

We calculated allele and genotype frequencies for both mutations in neonates. Expected genotype frequencies were estimated according to the Hardy-Weinberg equilibrium. We performed $\chi^{2}$ tests to verify Hardy-Weinberg equilibrium for all genotypes and to compare genotype and allele frequencies in different groups.

Parents received the results through the post and were invited in for free genetic counselling if their newborn had the genotype HH/YY. They were informed that, although the HH/YY genotype was a risk factor for developing iron overload in later life, it did not affect the health of the baby, but that family screening was advisable. If there was no response, the parents received a second letter and if there was no reply to this, a telephone call. The couples themselves were responsible for informing other family members. Genetic counselling was arranged at the request of the parents, during which it was stressed that the baby did not need any treatment or a special diet, but regular serum iron measurements as an adult was advised. Transferrin saturation and serum ferritin were not measured in the neonates.

\section{RESULTS}

The population of the Somme département is 551479 , of whom $84 \%$ are white. Using the Hardy-Weinberg equilibrium, and knowing that $\mathrm{C} 282 \mathrm{Y}$ allele has an allele frequency in this part of France of $\mathrm{q}=0.0577$, we found that within the white subset, about 1542 people are expected to be homozygous for the C282Y mutation in the HFE gene. ${ }^{73}$ Because of age and sex dependency of the manifestations of the symptoms, corrections were made using demographic data. In the white population, $21.1 \%$ of the women are aged 
$\geqslant 45$ years and $22.5 \%$ of the men are aged $\geqslant 35$ years, therefore we estimated that in this population 347 men and 325 women are C282Y homozygotes at risk of developing symptoms for HH. From 1996 to 2000, 288 patients fulfilled these age criteria and were identified as C282Y homozygotes ( 176 men; 112 women). Of the men, 107 have had at least $5 \mathrm{~g}$ of iron removed, giving a therapeutic penetrance of 30\% (107) 347), while 54 women were treated, giving a therapeutic penetrance of $16.6 \%(54 / 325)$. This gives an overall penetrance of $24 \%$ (161/672), a figure that, based on the calculations of Krawzcak et al, ${ }^{20}$ suggested that cascade screening was likely to be effective.

To see whether reverse cascade screening would be a potential and efficient screening strategy for haemochromatosis, we used Laplace-Baye's theorem to estimate the risk of parents having the homozygous genotype (HH/YY) if their child was either homozygous or heterozygous for the C282Y mutation. Using an average $\mathrm{Y}$ allele frequency (q) already known in the white population from previous studies $(q=0.0577)$, corresponding to a prevalence of about $1 / 300$, we calculated that if an $\mathrm{HH} / \mathrm{YY}$ newborn is identified, the probability for each parent being $\mathrm{HH} / \mathrm{YY}$ is q, which corresponds to a relative risk of $\mathrm{l} / \mathrm{q}$ compared with the general population-that is, they have a 17 fold greater risk. In the case of a $\mathrm{C} 282 \mathrm{Y}$ heterozygote, the probability of each parent being $\mathrm{HH} / \mathrm{YY}$ is $\mathrm{q} / 2$, corresponding to a relative risk of $1 / 2 \mathrm{q}$, or an 8.5 fold greater risk compared with that of the general population. Probability for both parents to be homozygous for the $\mathrm{C} 282 \mathrm{Y}$ mutation when a child is homozygous is $\mathrm{q}^{2}$.

We then carried out a pilot study to estimate the take up rate and to plan the logistics of neonatal screening study for haemochromatosis. Of those who first received an explanatory leaflet about the $\mathrm{HH}$ screening programme in neonates, $85 \%(105 / 123)$ agreed to neonatal genetic testing and family studies. Based on this result, we decided to organise neonatal screening for $\mathrm{HH}$ in Picardie.

We screened 7038 of 8280 babies born during the study period for the $\mathrm{C} 282 \mathrm{Y}$ and H63D mutations. We identified 19 C282Y homozygous babies from 18 families; two were brothers. Results for all genotypic groups for all ethnic groups are presented in table 1. Of 7038 newborns tested, 694 $(9.8 \%)$ had at least one non-white parent. There were no C282Y homozygotes in this group. Frequency of the C282Y allele in newborns with one or two non-white parents was 0.0200 compared with an allele frequency of 0.0526 in the group in which both parents were white $(p<0.001)$. The H63D allele frequency was 0.140 in the neonates with one or two non-white parents compared with 0.185 in the neonate group in which both parents were white $(\mathrm{p}=0.05)$. Genotype frequencies for $\mathrm{C} 282 \mathrm{Y}$ and H63D mutations followed HardyWeinberg equilibrium for five genotypes but not for compound heterozygotes $(\mathrm{HD} / \mathrm{CY}) \quad(\mathrm{p}<0.001)$. This discrepancy in $\mathrm{HD} / \mathrm{CY}$ had also been observed in a previous study of healthy adults from the same region. ${ }^{23}$

\section{Screening of families with $\mathrm{C} 282 \mathrm{Y}$ homozygous neonates}

Of 18 couples, 11 registered for genetic counselling with consent from both parents. Seven families did not respond to the letters they were sent, nor did they contact any medical staff. Counselling was performed 3-6 months after their baby was identified as a C282Y homozygote. Screening of these 22 parents identified five family members from four different families as C282Y homozygotes; in one family, the homozygotes were a parent and the baby's 7 year old brother, and in each of the other three families it was a parent. None of these families had a history of haemochromatosis.
Table 1 HFE genotypes among the neonate population (all ethnic groups)

\begin{tabular}{lccc}
\hline Genotype & $\begin{array}{l}\text { Observed } \\
(\mathbf{n}=7038)\end{array}$ & Expected & $\mathbf{p}$ \\
\hline $\mathrm{HH} / \mathrm{CC}$ & $4195(59.61)$ & $4173(59.30)$ & 0.6 \\
$\mathrm{HD} / \mathrm{CC}$ & $1952(27.74)$ & $1962(27.90)$ & 0.76 \\
$\mathrm{HH} / \mathrm{CY}$ & $491(6.97)$ & $531(7.54)$ & 0.07 \\
$\mathrm{DD} / \mathrm{CC}$ & $215(3.05)$ & $230(3.25)$ & 0.35 \\
$\mathrm{HD} / \mathrm{CY}$ & $166(2.36)$ & $125(1.77)$ & $<0.001^{*}$ \\
$\mathrm{HH} / \mathrm{YY}$ & $19(0.27)$ & $17(0.24)$ & 0.61 \\
\hline
\end{tabular}

Results are $\mathrm{n}(\%)$. p value: $\chi^{2}$ analysis for all genotypes. $Y$ allele frequency is $0.0494,95 \% \mathrm{Cl} 0.047$ to 0.0548 ; D allele frequency is $0.181,95 \% \mathrm{Cl}$ 0.172 to 0.190 . Ethnic group was self reported. *Genotype frequencies for $\mathrm{C} 282 \mathrm{Y}$ and $\mathrm{H} 63 \mathrm{D}$ variants were each in Hardy-Weinberg equilibrium; however, increased frequency of double heterozygotes (HD/ $C Y)$ was observed owing to partial linkage disequilibrium $(p<0.001)$ between these variants.

\section{Screening of families with C282Y heterozygous neonates}

Parents with a C282Y heterozygous baby could also request family screening. In this group, only 10 of 657 couples requested genetic testing. Five $\mathrm{C} 282 \mathrm{Y}$ homozygotes from two families were identified: one parent and an aunt in one family; one parent, an uncle, and a grandmother in the other. Again, there was no family history of haemochromatosis.

\section{Iron status in family members identified as $\mathrm{C} 282 \mathrm{Y}$ homozygotes}

A follow up was arranged for family members identified as $\mathrm{C} 282 \mathrm{Y}$ homozygotes. Baseline $\left(\mathrm{T}_{0}\right) \mathrm{T}_{\mathrm{sat}}$ and serum ferritin levels were determined in all the $10 \mathrm{C} 282 \mathrm{Y}$ homozygotes with a follow up measurement $\left(\mathrm{T}_{1}\right)$ at 6 months (table 2 ). Subject $\mathrm{V}$ was immediately treated by venesection in view of the high $\mathrm{T}_{\text {sat }}$. Subject II, following a second biochemical $\left(\mathrm{T}_{1}\right)$ estimation 3 months later, had elevated $\mathrm{T}_{\text {sat }}$, and treatment was recommended. After the second estimation, treatment was recommended for subjects III, IV, VII, and IX. All these patients had normal $C$ reactive protein levels. Subject IX, a woman aged 49 years, presenting with $88 \% \mathrm{~T}_{\text {sat }}$ and a serum ferritin of 100 was not treated originally, as her serum ferritin fell within the normal range $(50-200 \mu \mathrm{g} / \mathrm{l})$. Subsequently her serum ferritin has risen to $226 \mu \mathrm{g} / \mathrm{l}$ (table 2 ) and she is now receiving treatment. In total, all of the four men and two of the five women now require venesection. We aim to maintain their serum ferritin at $\leqslant 50 \mu \mathrm{g} / \mathrm{l}$ and $\mathrm{T}_{\text {sat }}$ levels at $\leqslant 25 \%$. Of the five HH/YY women, two women are being treated for haemochromatosis. Further questioning revealed that individuals II and V had symptoms of asthenia. An $x$ ray analysis showed a loss of joint space at metacarpophalangeal joints in individual II. All the other individuals were symptomless.

\section{Serum iron parameters in family members identified as compound heterozygotes}

There were 14 people (seven men, seven women; 10 of whom were grandparents) from 11 families identified with the genotype $\mathrm{HD} / \mathrm{CY}$. Only one, a grandfather (aged 50 years) had an increased serum ferritin level $(378 \mu \mathrm{g} / \mathrm{l})$ with a normal $\mathrm{T}_{\text {sat }}(39 \%)$ on initial testing. Six months later, his $\mathrm{T}_{\text {sat }}$ was $54 \%$ and serum ferritin $648 \mu \mathrm{g} / \mathrm{l}$, following which one $400 \mathrm{~mL}$ venesection was performed; following venesection, $\mathrm{T}_{\text {sat }}$ and serum ferritin values were $25 \%$ and $150 \mu \mathrm{g} / \mathrm{l}$, respectively. Twelve months later, his serum iron parameters remain within the normal range.

\section{DISCUSSION}

The penetrance of a genotype can be defined as the proportion of individuals with that particular genotype who 
Table 2 Iron status in family members identified as C282Y homozygotes

\begin{tabular}{|c|c|c|c|c|c|}
\hline $\begin{array}{l}\text { Subject } \\
\text { no. }\end{array}$ & Sex & $\begin{array}{l}\text { Age } \\
\text { (years) }\end{array}$ & $\begin{array}{l}\mathrm{T}_{\text {sat }}(\%) \\
\mathrm{T}_{0} / \mathrm{T}_{1}\end{array}$ & $\begin{array}{l}\text { Ferritin } \\
(\mu \mathrm{g} / \mathrm{l}) \mathrm{T}_{0} / \mathrm{T}_{1}\end{array}$ & $\begin{array}{l}\text { Amount } \\
\text { of iron } \\
\text { removed }(\mathrm{g})^{*}\end{array}$ \\
\hline I & $M \dagger$ & 7 & $39 / 42$ & $190 / 220$ & NA \\
\hline II & $\mathrm{M} \dagger$ & 34 & $63 / 73 \S$ & $430 / 680 \S$ & 6.5 \\
\hline III & $M \dagger$ & 32 & $47 / 59$ & $342 / 525$ & 5.25 \\
\hline IV & $M \ddagger$ & 41 & $48 / 75$ & $150 / 542$ & 6.0 \\
\hline V & $M \ddagger$ & 24 & $79 / N D$ & $672 / N D$ & 6.5 \\
\hline VI & $\mathrm{F} \dagger$ & 30 & $25 / 33$ & $15 / 46$ & NA \\
\hline VII & $\mathrm{F} \ddagger$ & 27 & $78 / 89$ & $137 / 634$ & 5.5 \\
\hline VIII & $\mathrm{F} \dagger$ & 23 & $10 / 22$ & $12 / 55$ & NA \\
\hline IX & $\mathrm{F} \ddagger$ & 49 & $88 / 92$ & $100 / 226$ & 0.5 \\
\hline$X$ & $\mathrm{~F} \ddagger$ & 27 & $65 / 68$ & $32 / 82$ & NA \\
\hline
\end{tabular}

*To maintain to $T_{\text {sat }} \leqslant 25 \%$ and ferritin $\leqslant 50 \mu \mathrm{g} / \mathrm{l}$. Subject identified through: $† C 282 Y$ homozygous newborn; $\ddagger C 282 Y$ heterozygous newborn. Transferrin saturation $\left(\mathrm{T}_{\text {sat }} \%\right)$ and serum ferritin $(\mu \mathrm{g} / \mathrm{l})$ at genotyping $\left(T_{0}\right) ; T_{1}$ is 6 months or $\$ 3$ months past $T_{0}$. NA, not applicable.

have the associated phenotype. If these individuals then present with clinical symptoms, this can then be regarded as clinical penetrance. Based on questionnaire data or clinical observation, the prevalence of symptoms associated with haemochromatosis is common in both C282Y homozygotes and individuals with the wildtype genotype. Therefore, the clinical penetrance of the HH/YY genotype with regard to these symptoms is low. ${ }^{15}{ }^{17}$ Biochemical penetrance, the finding of increased serum iron indices, is much higher than the clinical penetrance. Indeed, most $\mathrm{C} 282 \mathrm{Y}$ homozygotes display a common biochemical phenotype, namely an elevated transferrin saturation level that is found with an increased serum ferritin level in up to $77 \%$ of men and $56 \%$ of women. ${ }^{24}$ Heterogeneity in the presentation of HFE associated haemochromatosis, together with the fact that biochemical presentation is both age and gender specific, present difficulties in comparing studies involving the HH/YY genotype. ${ }^{25}$ Because of this, the penetrance of the $\mathrm{HH} / \mathrm{YY}$ genotype has proved difficult to establish. Therefore, in our study we took a different approach by examining therapeutic penetrance, by referring it to the actual iron burden. The assumption is that if a genetic disease is treated, thus preventing complications, the genotype giving rise to the disease is fully penetrant. Rather than waiting for massive accumulation of iron, the demonstration of increased iron stores was chosen as the indication for treatment. Although different definitions cannot give rise to comparisons, the removal of at least $5 \mathrm{~g}$ of iron in order to restore normal iron biochemical parameters seems a useful definition of penetrance, particularly, as this has long been part of the definition of the disease, yet more recent reports have not considered this factor in describing what is and what is not haemochromatosis.

In this study, we identified 288 of a possible 672 haemochromatosis patients who had first been referred to consultants because they had high serum iron parameters and/or clinical manifestations including arthralgia and/or fatigue. If the definition of disease is based on quantitative phlebotomy, the removal of $5 \mathrm{~g}$ of iron over a period of less than a year (that is, the "therapeutic penetrance"), 161 patients met this criterion, but 127 of the $288 \mathrm{C} 282 \mathrm{Y}$ homozygotes did not. It is possible that among the remaining predicted $384 \mathrm{C} 282 \mathrm{Y}$ homozygotes, some may have undiagnosed haemochromatosis, thus the observed therapeutic penetrance of the HH/YY genotype of 24\% (161/672) may well be an underestimate. Nevertheless, in a population with this condition, widespread population screening for haemochromatosis may be advantageous.
Neonatal screening for HH has been undertaken by other groups purely as a means of population screening to establish the frequencies of the C282Y and H63D alleles. ${ }^{26} 27$ Our strategy combines population wide and reverse cascade screening of $\mathrm{C} 282 \mathrm{Y}$ homozygous newborns to enable early detection of disease in parents and relatives. The neonatal period is an excellent time to access family members of different generations and arguably an ideal time to detect early haemochromatosis, as the majority of the parents of the newborns were $<35$ years of age in this study.

Initially, this study was designed to screen for the C282Y and H63D mutations where both parents were whites, but was later expanded as universal screening at the request of non-white parents. The percentage of newborns were missed was $15 \% ; 12 \%$ due to staff forgetfulness, and 3\% to parents declining the test. Thus, the acceptance rate for neonatal screening for $\mathrm{C} 282 \mathrm{Y}$ and $\mathrm{H} 63 \mathrm{D}$ was high; the parents were aware of the implications for themselves and their families. Traditionally, population screening for haemochromatosis has had no psychosocial impact on anxiety, mental health, or physical health status. ${ }^{28}$ Anxiety was never given as a reason for refusal of neonatal screening, possibly because haemochromatosis is treatable. ${ }^{29}$ Both parents were unanimous in their decision to accept or refuse neonatal testing. In France, current law prevents disclosure of genetic testing results to insurance companies, banks, or employers, and hence this is unlikely to be a reason for refusal. To obtain a high acceptance rate for genetic screening programmes elsewhere, it may be necessary to enact local law to prevent disclosure of genetic information to limit discrimination by insurance companies, employers and banks. Currently, neonatal screening for PKU, hypothyroidism, haemoglobinopathies, and CF does not require parental permission, as these are not DNA based tests. However if a result justifies DNA analysis (for example, in CF) parental consent is required.

Although acceptance of neonatal screening was high, only 11 of the 18 families (61\%) with homozygous newborns accepted further testing. The take up rate for further testing in families with C282Y heterozygous babies was much lower compared with those with homozygous newborns; only 10 of 657 families (1.6\%) responded despite all the information and support provided. In these families, increased personal contact with parents might have increased the response rate, $^{30}$ but this would have been time consuming, and required more staff and resources. However, despite the poor response, reverse cascade screening identified five C282Y homozygotes from the 10 families with $\mathrm{C} 282 \mathrm{Y}$ heterozygote newborns. These results demonstrate that parents were willing for their baby to be screened, yet unwilling to be screened themselves. Our screening strategy benefits both parents equally (table 2 ). A previous study showed that it was difficult to recruit young men, the very group most likely to benefit from screening programmes for $\mathrm{HH} .{ }^{31}$ If this lack of willingness to participate in screening programmes is prevalent among the adult population, it has wide implications for preventative screening in a wide range of diseases. Screening for several diseases at once is the most cost effective approach, and neonatal screening is the most cost effective time. It also lends itself to the creation of a centralised register, allowing longitudinal studies on disease penetrance, not just for $\mathrm{HH}$ but also for other diseases that might be incorporated later into disease surveillance programmes.

Using this strategy of reverse cascade screening, we have identified 10 previously unknown C282Y homozygotes, of whom six (four men and two women) are now being treated by regular venesection, thus preventing complications of the disease and restoring normal life expectancy. Annual follow ups have been proposed for the other three women who are 
C282Y homozygotes. Close monitoring has been proposed for one individual, the 7 year old son of subject II (table 3 ), whose serum ferritin rose by more than $20 \%$ in 1 year. Of 14 compound heterozygotes, one required treatment, despite the mean (SD) age of this group being 49 (2.3) years.

It should be noted that all four HH/YY men identified in this study had elevated serum iron parameters 1 year after diagnosis. It is important to appreciate the significance of raised serum iron parameters in the absence of clinical disease. In particular, arthritis due to joint damage associated with haemochromatosis is not always reversible. ${ }^{32}$ It should be noted that the youngest patient identified was aged 24 years and the oldest 49 years. Increased serum iron parameters in one so young indicates that such individuals are likely to develop haemochromatosis unless treated. Therefore, our approach allows the early identification of $\mathrm{HH}$ with the aim of preventing clinical disease. The large number of relatives requiring treatment for haemochromatosis suggests that our figure for therapeutic penetrance of $24 \%$ may well be an underestimate for this part of France.

This study raises several questions and issues. When do we actually treat someone with $\mathrm{HH} / \mathrm{YY}$ genotype with raised a $\mathrm{T}_{\text {sat }} \%$ but normal ferritin levels? How often do we repeat serum ferritin level measurements? It has also been questioned whether families with heterozygous newborns should be investigated. An unexpected finding was the identification of five homozygotes from 10 of such families, a number similar to that identified through reverse cascade screening of homozygous newborns. Although the number of such families tested is low, it shows that enrichment in HH/YY genotypes in families from heterozygous babies has to be taken into account in a future screening strategy. All family members diagnosed were very grateful for the early detection of their haemochromatosis.

Reverse cascade screening offers the possibility of early clinical intervention, preventing morbidity and mortality associated with $\mathrm{HH}$. Cost effective preventive measures include regular blood donation and reduction of alcohol intake. A major difficulty with any neonatal screening programme is making sure that information is retained for the future. Screening newborns is not just for the benefit of their families, provided their genotypes are not lost. A register is vital. Setting up a local haemochromatosis register could play a key role in coordinating a multidisciplinary approach to the management of patients, and facilitate family and longitudinal studies for assessment of penetrance of the $\mathrm{HH} /$ YY genotype. Childless couples are excluded in the initial screening step, but may be screened through being a relative. For reverse cascade screening to be successful, effective genetic counselling and universally available medical information sheets are vital.

In summary, reverse cascade screening for $\mathrm{HH}$ is very effective in identifying previously unknown affected individuals. Reverse cascade screening from a neonate who is $\mathrm{HH} /$ $\mathrm{CY}$ or HH/YY identified 10 homozygotes from 80 parents and relatives $(1 / 8)$, which is a high percentage compared with random screening. ${ }^{20}$

\section{ELECTRONIC DATABASE INFORMATION}

Accession numbers and URLs for data in this article: Genbank, http://www.ncbi.nlm.nih.gov/Genbank/ (for haemochromatosis gene (HFE)); and Online Mendelian Inheritance in Man (OMIM), http://www.ncbi.nlm.nih.gov/omim/ (for HH (OMIM \#235200)).

\section{ACKNOWLEDGEMENTS}

We thank all the medical staff in the participating hospitals who helped collect the samples. We are indebted to Professor Sir
D Weatherall and Professor S Lay Thein for encouragement and critical assessment of the manuscript.

\section{Authors' affiliations}

E Cadet, J Rochette, Department of Medical Genetics \& UMR-INERIS, Centre Hospitalo-Universitaire et Faculté de Médecine, Amiens, France

D Capron, Department of Hepato-Gastroenterologie, Centre HospitaloUniversitaire et Faculté de Médecine, Amiens, France

M Gallet, M-L Omanga-Léké, Department of Néonatalogie, Centre Hospitalo-Universitaire et Faculté de Médecine, Amiens, France H Boutignon, Department of Néonatalogie, Centre Hospitalier de Compiègne, France

C Julier, Institut Pasteur, Paris, France

K J H Robson, MRC Molecular Haematology Unit, Weatherall Institute of Molecular Medicine, Oxford, UK

This work was funded by EC contract QLRT-1999-02237 and le Pôle Génie Biologique et Médical, UPJV-UTC from Picardie

Competing interests: none declared

\section{REFERENCES}

1 Bothwell TH, Charlton RW, Motulsky AG. Hemochromatosis. In: Scriver CR Beaudet AL, Sly WS, Valle D, eds. The metabolic and molecular bases of inherited disease. New York: McGraw-Hill, 1995:2237-69.

2 Jouanolle AM, Gandon G, Blayau M, Campion ML, Yaouang J, Mosser J, Fergelot P, Chauvel B, Bouric P, Carn G, Andrieux N, Le Gall J-Y, David V. Haemochromatosis and HLA-H. Nature Genet 1996;14:251-2.

3 Feder JN, Gnirke A, Thomas W, Tsuchihashi Z, Ruddy DA, Basava A, Dormishian F, Domingo R Jr, Ellis MC, Fullan A, Hinton $L M$, Jones NL, Kimmel BE, Kronmal GS, Lauer P, Lee VK, Loeb DB, Mapa FA, McClelland E, Meyer NC, Mintier GA, Moeller N, Moore T, Morikang E, Prass CE, Quintana L, Starnes SM, Schatzman RC, Brunke KJ, Drayna DT, Risch NJ, Bacon BR, Wolff RK. A novel MHC class I-like gene is mutated in patients with hereditary haemochromatosis. Nature Genet 1996;13:399-408.

4 Niederau C, Fischer R, Purschel A, Stremmel W, Haussinger D, Strohmeyer G. Long-term survival in patients with hereditary hemochromatosis. Gastroenterol 1996;110:1107-19.

5 Burke W, Thomson E, Khoury MJ, McDonnell SM, Press N, Adams PC, Barton JC, Beutler E, Brittenham G, Buchanan A, Clayton EW, Cogswell ME, Meslin EM, Motulsky AG, Powell LW, Sigal E, Wilfond BS, Collins FS. Hereditary hemochromatosis gene discovery and its implications for population-based screening. JAMA 1998;280:172-8

6 Niederau C, Niederau CM, Lange S, Littauer A, Abdel-Jalil N, Maurer M, Häussinger D, Strohmeyer G. Screening for hemochromatosis and iron deficiency in employees and primary care patients in western Germany. Ann Intern Med 1998;128:337-45.

7 Rochefte J, Capron D, Capron JP, Julier C. Screening for hereditary haemochromatosis. Am J Gastro 2000;95:1368-9.

8 McLaren CE, McLachlan GJ, Halliday JW, Webb SI, Leggett BA Jazwinska EC, Crawford DHG, Gordeuk VR, McLaren GD, Powell LW. Distribution of transferrin saturation in an Australian population: relevance to the early diagnosis of hemochromatosis. Gastroenterol 1998;1 14:543-9.

9 Adams PC, Kertesz AE, McLaren CE, Barr R, Bamford A, Chakrabarti S. Population screening for hemochromatosis: a comparison of unbound ironbinding capacity, transferrin saturation, and C282Y genotyping in 5,211 blood donors. Hepatology 2000;31:1160-4.

10 Adams PC, Valberg LS. Screening blood donors for hereditary hemochromatosis:decision analysis model comparing genotyping to phenotyping. Am J Gastro 1999:94:1593-600.

11 Powell LW. Diagnosis of hemochromatosis. Semin Gastrointest Dis 2002;13:80-8

12 Bulaj ZJ, Ajioka RS, Phillips JD, LaSalle BA, Jorde LB, Griffen LM, Edwards CQ, Kushner JP. Disease-related conditions in relatives of patients with hemochromatosis. N Engl J Med 2000;343:1529-35.

13 Crawford DHG, Jazwinska EC, Cullen LM, Powell LW. Expression of HLAlinked hemochromatosis in subjects homozygous or heterozygous for the C282Y mutation. Gastroenterol 1998;114:1003-8.

14 Bacon BR, Olynyk JK, Brunt EM, Britton RS, Wolff RK. HFE genotype in patients with hemochromatosis and other liver diseases. Ann Intern Med 1999; 130:953-62.

15 Beutler E, Felitti VJ, Koziol JA, Ho NJ, Gelbart T. Penetrance of $845 \mathrm{G} \rightarrow \mathrm{A}$ (C282Y) HFE hereditary haemochromatosis mutation in the USA. Lancet 2002;359:211-18

16 Cox T, Rochette J, Camaschella C, Walker A, Robson K. Clinical haemochromatosis in HFE mutation carriers. Lancet 2002;360:412.

17 McCune CA, Al-Jader LN, May A, Hayes SL, Jackson HA, Worwood M. Hereditary haemochromatosis: only $1 \%$ of adult HFE C282Y homozygotes in South Wales have a clinical diagnosis of iron overload. Hum Genet 2002;111:538-43.

18 Wallace DF, Dooley JS, Walker AP. A novel mutation of HFE explains the classical phenotype of genetic haemochromatosis in a C282Y heterozygote. Gastroenterol 1999:116:1409-12.

19 Olynyk JK, Cullen DJ, Aquilia S, Rossi E, Summerville L, Powell LW. A population-based study of the clinical expression of the hemochromatosis gene. N Eng J Med 1999;341:718-24. 
20 Krawczak M, Cooper DN, Schmidtke J. Estimating the efficacy and efficiency of cascade genetic screening. Am J Hum Genet 2001;69:361-70.

21 Merryweather-Clarke AT, Pointon JJ, Shearman JD, Robson KJH. Global prevalence of putative haemochromatosis mutations. J Med Genet 1997:34:275-8.

22 Merryweather-Clarke AT, Pointon JJ, Shearman JD, Robson KJH, Jouanolle AM, Mosser A, David V, Le Gall J-Y, Halsall DJ, Elsey TS, Kelly A, Cox TM, Clare M, Bomford A, Vandwalle JL, Rochette J, Borot N, Coppin H Roth M-P, Ryan E, Crowe J, Totaro A, Gasparini P, Roetto A, Camaschella C, Darke C, Wallace DF, Saeb-Parsy K, Dooley JS, Worwood M, Walker AP. Polymorphism in intron 4 of HFE does not compromise haemochromatosis mutation results. Nature Genet 1999;23:271

23 Cadet E, Capron D, Perez AS, Crépin SN, Arlot S, Ducroix J-P, Dautréaux M, Fardellone P, Leflon P, Merryweather-Clarke AT, Livesey KJ, Pointon JJ, Rose P, Harcourt J, Emery J, Sueur JM, Feyt R, Robson KJH, Rochette J. A targeted approach significantly increases the identification rate of patients with undiagnosed haemochromatosis. J Intern Med 2003;253:217-24.

24 Allen KJ, Warner B, Delatycki MB. Clinical haemochromatosis in HFE mutation carriers. Lancet 2002;360:412-13 (author reply 413-14).

25 Ajioka RS, Kushner JP. Clinical consequences of iron overload in hemochromatosis homozygotes. Blood 2003;101:3351-3 (discussion 3354-8).
26 Cullen LM, Summerville L, Glassick TV, Crawford DHG, Powell LW, Jazwinska EC. Neonatal screening for the hemochromatosis gene defect. Blood 1997;90:4236-37.

27 Merryweather-Clarke AT, Simonsen H, Shearman JD, Pointon JJ, NørgaardPedersen $\mathrm{B}$, Robson $\mathrm{KJH}$. A retrospective anonymous pilot study in screening newborns for HFE mutations in Scandinavian populations. Human Mutation 1999;13:154-9.

28 Pedersen PPE, Husum K, Milman K. A user persepective on genetic screening for hemochromatosis. Preliminary results of the psychological effects on HFE genotyping and level of information in a population of Danish man. Bioiron 2003, Bethesda, Maryland, USA, 2003.

29 Power TE, Adams PC. Psychosocial impact of C282Y mutation testing for hemochromatosis. Genet Test 2001;5:107-10.

30 McDonnell SM, Phatak PD, Felitti V, Hover A, McLaren GD. Screening for hemochromatosis in primary care settings. Ann Intern Med 1998;129:962-70.

31 Deugnier $Y$, Jouanolle A-M, Chaperon J, Moirand R, Pithois C, Meyer J-F, Pouchard M, Lafraise B, Brigand A, Caserio-Schoenemann C, Adams P, Le-Gall J-Y, David V. Gender-specific phenotypic expression and screening strategies in C282Y-linked haemochromatosis. A study of 9396 French people. Br J Haematol 2002;118:1170-8.

32 Powell LW, Jazwinska E, Halliday JW. Primary iron overload. In: Brock JH, Halliday JW, Pippard MJ, Powell LW, eds. Iron metabolism in health and disease. London: WB Saunders Ltd, 1994;227-70.

\section{bmjupdates+}

bmjupdates+ is a unique and free alerting service, designed to keep you up to date with the medical literature that is truly important to your practice.

bmiupdates+ will alert you to important new research and will provide you with the best new evidence concerning important advances in health care, tailored to your medical interests and time demands.

Where does the information come from?

bmiupdates+ applies an expert critical appraisal filter to over 100 top medical journals A panel of over 2000 physicians find the few 'must read' studies for each area of clinical interest

Sign up to receive your tailored email alerts, searching access and more...

www.bmjupdates.com 